\title{
Dermatoglyphics as a Noninvasive Tool for Predicting Dental Caries in Cerebral Palsy and Healthy Children: An In Vivo Study
}

\author{
Rani Somani ${ }^{1}$, Monika P Gupta ${ }^{2}$, Shipra Jaidka ${ }^{3}$, Deepti J Singh ${ }^{4}$, Vishal Puri ${ }^{5}$, Dilip Kumar ${ }^{6}$
}

\begin{abstract}
Aim: To find the association of dermatoglyphics and dental caries in normal and cerebral palsy (CP) children.

Materials and methods: A total of 150 children of age group 6-12 years were selected and divided into three equal groups. Group I constituted of $50 \mathrm{CP}$ caries-active children, group II constituted of 50 healthy caries active children, and group III consisted of 50 healthy caries-free children. World Health Organization (WHO) criteria were used for diagnosis and recording of decayed, missing, filled teeth (DMFT)/deft scores. Fingerprints of both hands were taken using a stamp pad and analyzed using the Cummin and Midlo method.

Results: The results were statistically analyzed using one-way analysis of variance (ANOVA) and post hoc Tukey's honestly significant difference (HSD). The data for the entire study were calculated using statistical package for social sciences (SPSS) statistical software 19.0 version. The mean DMFT/ deft score was the highest for the CP caries-active group compared to the healthy caries-active and healthy caries-free children. Dermatoglyphic pattern distribution in the CP caries-active group showed more whorls and that in the healthy caries-free group showed more arches. Intergroup comparisons for DMFT/deft and dermatoglyphic patterns were significant except between CP caries-active children and healthy caries-active children. Conclusion: Association of dermatoglyphics and dental caries was observed among CP caries-active children, healthy caries-active children, and healthy caries-free children. This association can be helpful in identifying the possible genetic predisposition and early prediction of dental caries in CP children, so as to initiate oral health measures at an early stage.
\end{abstract}

Clinical significance: Maintaining oral hygiene has always been a challenge in children because of many difficulties like behavior management and lack of dexterity, and it becomes all the more difficult in the case of children with special needs. Dermatoglyphics can be proven to be a very useful, noninvasive, and economical tool for the preliminary diagnosis of diseases of suspected genetic origin like dental caries and CP.

Keywords: Cerebral palsy, Dental caries, Dermatoglyphics, Fingerprint patterns.

International Journal of Clinical Pediatric Dentistry (2019): 10.5005/jp-journals-10005-1630

\section{INTRODUCTION}

Smile is the most effective way of interacting for many children with developmental disabilities, but they often have unmet complex oral health care needs as well as significant physical and cognitive limitations which may affect their quality of life and ability to eat, sleep, and function. As per Census 2011, in India, out of the $121 \mathrm{Cr}$ populations, about $2.68 \mathrm{Cr}$ persons, which are $2.21 \%$ of the total population, are suffering from some kind of disability. Children with disabilities may have more marked oral problems either because of their actual disability or for other medical, economic, and social reasons or even because of their parents' having difficulty in carrying out proper regular oral hygiene measures. Some of the common forms of disability are mental retardation, cerebral palsy (CP), autism, attention deficient hyperactive syndrome, Down syndrome, etc. One of the most common forms of neuromuscular disabilities affecting children is $C P$, the worldwide incidence being 2 to 2.5 per 1,000 live births, and in India, the incidence being 3.3 in 1,000 live births.'

CP describes a group of permanent disorders involving movement and posture development that cause activity limitations. Perinatal asphyxia is found to be the cause of the disease in only $6-8 \%$ of the cases, whereas prenatal risk factors account for approximately $75 \%$ of CP cases. $^{2}$ Genetic factors play a role in the genesis of $\mathrm{CP}$, and genetically determined causes are identified in $40 \%$ of CP patients. Children suffering from CP have motor dysfunctions which are often accompanied by disturbances of
${ }^{1-4}$ Department of Pedodontics and Preventive Dentistry, Divya Jyoti (DJ) College of Dental Sciences and Research, Modinagar, Ghaziabad, Uttar Pradesh, India

${ }^{5}$ Department of Pediatrics, Military Hospital, Meerut, Uttar Pradesh, India

${ }^{6}$ Department of Pathology, Max Superspeciality Hospital, Saket, New Delhi, India

Corresponding Author: Rani Somani, Department of Pedodontics and Preventive Dentistry, Divya Jyoti (DJ) College of Dental Sciences and Research, Modinagar, Ghaziabad, Uttar Pradesh, India, Phone: +919810950754, e-mail: somanirani@gmail.com

How to cite this article: Somani R, Gupta MP, et al. Dermatoglyphics as a Noninvasive Tool for Predicting Dental Caries in Cerebral Palsy and Healthy Children: An In Vivo Study. Int J Clin Pediatr Dent 2019;12(3):237-242.

Source of support: Nil

Conflict of interest: None

sensation, perception, cognition, communication, and behavior. These are attributed to nonprogressive disturbances occurring in the developing fetal or infant brain. These neuromuscular problems inherent in CP can affect the oral health significantly, thereby acting as a barrier to oral care access, thus increasing caries susceptibility.

Dental caries is known to be a complex, chronic, multifactorial most prevalent oral disease having a genetic basis. The genetic basis

() The Author(s). 2019 Open Access This article is distributed under the terms of the Creative Commons Attribution 4.0 International License (https://creativecommons. org/licenses/by-nc/4.0/), which permits unrestricted use, distribution, and non-commercial reproduction in any medium, provided you give appropriate credit to the original author(s) and the source, provide a link to the Creative Commons license, and indicate if changes were made. The Creative Commons Public Domain Dedication waiver (http://creativecommons.org/publicdomain/zero/1.0/) applies to the data made available in this article, unless otherwise stated. 
of dental caries is established by the twin studies of global evidence of dental caries heritability and studies of inherited variations in dental enamel. ${ }^{3}$

The epithelium of the finger buds, the enamel, which is the most susceptible dental tissue to caries, as well as the early fetal brain development have an ectodermal origin and develop at the same time of intrauterine life, in the 6th to 7 th week of gestation and completed by 20 th to 24 th week of gestation. ${ }^{4}$ This indicates that the genetic message present in the genetic makeup of a person normal or with disability is transmitted through this period and is reflected by dermatoglyphics. ${ }^{5}$ Thus, the resulting ridge configurations are genetically determined and also influenced and modified by environmental factors.

Dermatoglyphics is the study of fingerprints and is considered to be a window of congenital abnormalities. Diagnosing dental caries in CP children is a very challenging task for the dentist and providing treatment is all the more difficult. Thus, dermatoglyphics being a genetic marker of dental caries can be used as an indicator for dental caries much before its initiation, giving an opportunity to the dentist to take preventive measures to help combat the development of the disease in an early stage. So, this study was undertaken to determine an association of dermatoglyphics with dental caries in normal and CP children.

\section{Aims and Objectives}

To evaluate and compare the dermatoglyphics and dental caries in $\mathrm{CP}$ caries-active children, healthy caries-active children, and healthy caries-free children.

\section{Materials and Methods}

The present in vivo study was carried out in Divya Jyoti (DJ) College of Dental Sciences, Modinagar, in collaboration with Asha School, Military Hospital, Meerut Cantonment, Disha School, Meerut, and KV Punjab Lines, Meerut Cantonment. An ethical clearance was obtained from the institutional ethical committee prior to the study (DJD/2BC/2017/A-2C). Written consent was taken from the principals of the concerned schools on behalf of children after explaining them the procedure of the study.

A total of 150 students of the age group 6-12 years were taken. These were divided into three groups. Fifty children were taken from the institutional schools (Asha School and Disha School, Meerut), which constituted group I with the inclusion criteria being the presence of caries and no other systemic condition other than CP. Hundred children were taken from KV Punjab Lines, Meerut Cantonment, which constituted group II $(N=50)$ and group III $(N=50)$, the inclusion criterion for the group II children was the presence of caries without any systemic condition and those for group III was complete absence of caries and absence of any systemic condition.

\section{Recording of the DMFT/deft Index}

Case history was recorded using "Dentition status and treatment needs," (WHO basic oral health assessment form 1997). ${ }^{6}$ Dental caries was recorded using the DMFT and deft index for permanent and primary teeth using type 3 examination. Intraoral examination of the children with CP was carried out in the presence of their school teacher or the care giver, so as to gain cooperation from the children. The overall values of DMFT and deft were evaluated separately (Figs 1 and 2).

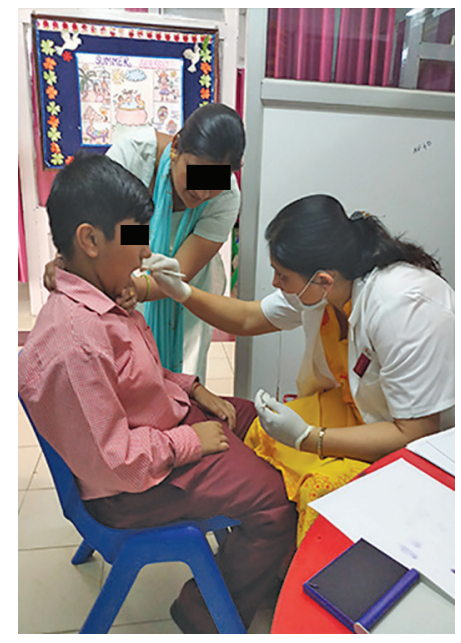

Fig. 1: Recording of DMFT/deft in CP children

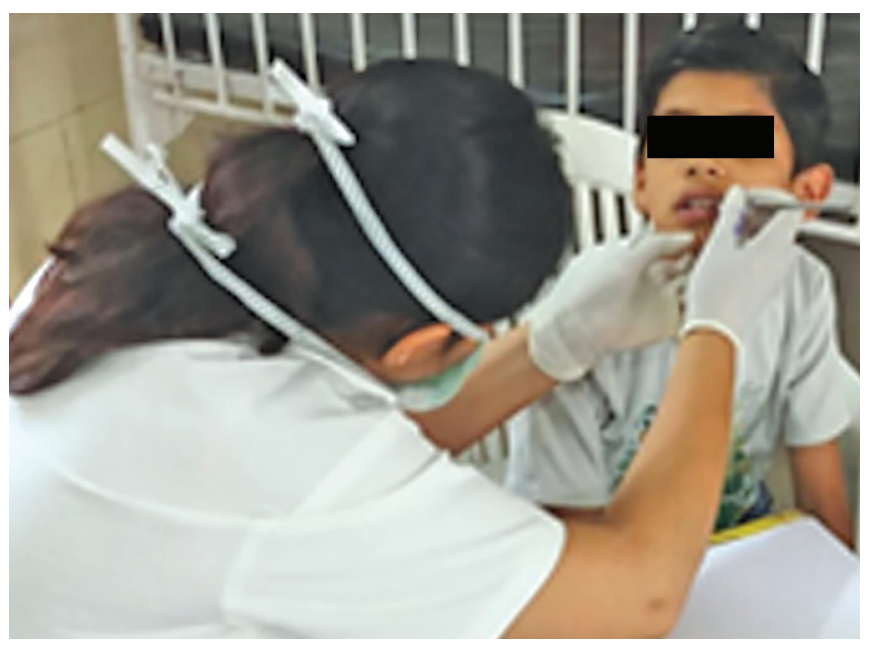

Fig. 2: Recording of DMFT/deft in normal children

\section{Dermatoglyphic Pattern Recording and its Interpretation}

\section{Fingerprint Recording}

Fingerprints were recorded using the ink method described by Cummin and Midlo. Before starting the procedure, the hands of the children were washed with antiseptic solution using cotton and were allowed to dry. The fingers were guided and pressed lightly on the ink pad and then guided by the examiner and pressed firmly on the A4 sheets which were kept on a firm surface. The children were made to do this repeatedly on 2 to $3 \mathrm{~A} 4$ sheets placed simultaneously till clear prints were obtained.

\section{Method of Reading Fingerprints}

The fingerprints were observed in a sequential manner and were analyzed from the fourth digit of the left hand moving in a clockwise direction till the thumb and then were analyzed from the thumb of the right hand moving in a clockwise direction till the fourth finger. These dermatoglyphic patterns were analyzed with the help of a magnifying glass (10X) (Figs 3 and 4).

\section{Dermatoglyphic Pattern Analysis}

The ridge patterns on the distal phalanges of the fingertips observed were divided into three groups: arches, loops, and whorls. ${ }^{7}$ 


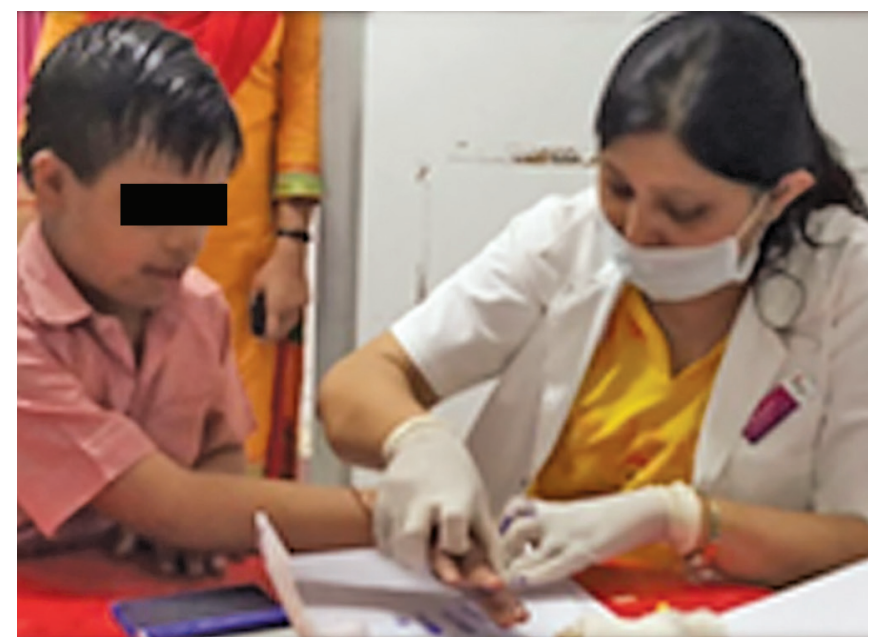

Fig. 3: Recording of dermatoglyphic patterns in CP children

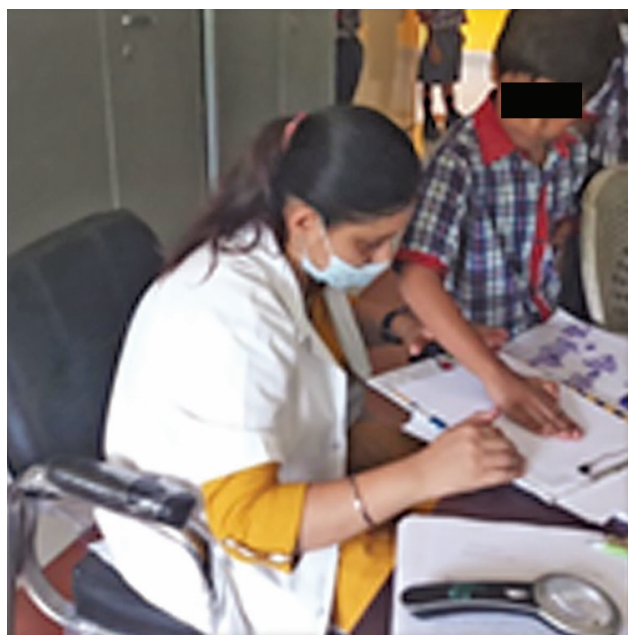

Fig. 4: Recording of dermatoglyphic patterns in normal children

\section{(i) Arches}

These are the simplest patterns found on fingertips. These are formed by succession of more or less parallel ridges, which traverse the pattern area and form a curve that is concave proximally. Sometimes, the curve is gentle; at other times, it swings more sharply, so that it may also be designated as a low or high arch, respectively.

\section{(ii) Loops}

These are the most common patterns on fingertips. A series of ridges enter the pattern area on one side of the digit, recurve abruptly, and leave the pattern area on the same side. Loops may vary considerably in shape and size. They may be large or small, tailor short, and vertically or horizontally oriented.

\section{(iii) Whorls}

These are any ridge configurations with two or more tri-radii. One tri-radius is on the radial side and the other on the ulnar side of the pattern. Tri-radii are formed by the confluence of three ridge systems that form angles of approximately $120^{\circ}$ with one another.

\section{Results}

The obtained data were collected and statistically analyzed with one-way ANOVA and Tukey's honestly significant difference (HSD)
Table 1: Mean values of DMFT/deft of various groups

\begin{tabular}{|c|c|c|c|c|c|c|c|}
\hline \multirow[b]{2}{*}{ Various groups } & \multirow[b]{2}{*}{$N$} & \multicolumn{2}{|l|}{ Mean } & \multicolumn{2}{|l|}{$S D$} & \multicolumn{2}{|l|}{ SEM } \\
\hline & & $D M F T$ & Deft & $D M F T$ & Deft & $D M F T$ & Deft \\
\hline Group I & 50 & 0.88 & 2.70 & 1.319 & 1.992 & 0.18657 & 0.281 \\
\hline Group II & 50 & 0.58 & 1.96 & 0.810 & 1.428 & 0.11461 & 0.201 \\
\hline Group III & 50 & 0.00 & 0.00 & 0.00 & 0.00 & 0.00 & 0.00 \\
\hline
\end{tabular}

Group I: CP caries-active children; group II: healthy caries-active children; group III: healthy caries-free children; SD: standard deviation; SEM: standard error mean

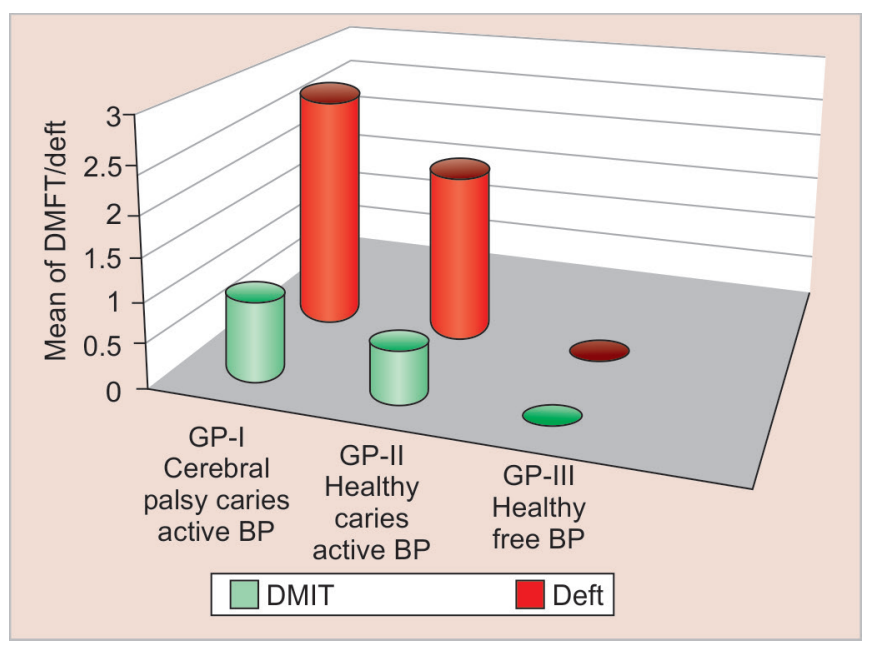

Fig. 5: Mean values of DMFT/deft

test using SPSS statistical software 19.0 versions. A $p$ value of 0.05 or less was considered for statistical significance.

A steady decrease in the values of DMFT/deft was seen from group I (CP caries-active group) to group III (healthy caries-free group) with mean values of $0.88 / 2.70,0.58 / 1.96$, and $0.00 / 0.00$ (Table 1 and Fig. 5). Intergroup comparison using post hoc analysis by Tukey's HSD test showed that all the intergroup comparisons were found to be statistically nonsignificant except when group III (healthy caries-free group) was compared with group I (CP cariesactive group) and group II (healthy caries-active group) with a $p$ value $\leq 0.05$ (Table 2 ).

The mean value of arches was found to be the highest in group III (healthy caries-free group), which was 4.152, and it was found to be the lowest for group II (healthy caries-active group) which was 2.270. Group I (CP caries-active group) showed a mean value of arches (3.180) which was more than that of group II (healthy caries-active group), but less than that of group I (CP caries-active group) (Table 3, Fig. 6).

The mean value of whorls showed a decrease in values from group I (CP caries-active group), which was 4.740, to group II (healthy caries-active children), which was 4.420, and then group III (healthy caries-free children), which was 3.200 (Table 3 and Fig. 6). All the intergroup comparisons for arches and whorls were found to be statistically significant except when group I (CP caries-active children) was compared with group II (healthy caries-active children) (Table 4).

The mean value of loops was found to be the highest for group III (healthy caries-free children), which was 3.002, followed by group II (healthy caries-active children), which was 4.420 , and was the least for group I (CP caries-active children), which was 2.140 (Table 3 and Fig. 6). However, the intergroup comparisons were found to be statistically insignificant (Table 4). 
Dermatoglyphics as a Noninvasive Tool for Predicting Dental Caries in Cerebral Palsy and Healthy Children

Table 2: Post-Tukey's analysis of intergroup comparison of DMFT and deft

\begin{tabular}{|c|c|c|c|c|c|c|}
\hline \multirow[b]{2}{*}{ Intergroup comparison } & \multicolumn{2}{|c|}{ Mean difference } & \multicolumn{2}{|l|}{$S E$} & \multicolumn{2}{|l|}{$p$-value } \\
\hline & DMFT & Deft & DMFT & Deft & $D M F T$ & Deft \\
\hline Group I vs group II & 0.30000 & -0.74000 & 0.17878 & 0.28304 & 0.095 & 0.100 \\
\hline Group I vs group III & 0.88000 & 2.70000 & 0.17878 & 0.28304 & $0.001^{\mathrm{a}}$ & $0.001^{\mathrm{a}}$ \\
\hline Group II vs group III & 0.58000 & 1.96000 & 0.17878 & 0.28304 & $0.001^{\mathrm{a}}$ & $0.001^{\mathrm{a}}$ \\
\hline
\end{tabular}

a Statistically significant with $p$-value $\leq 0.05$; SE: standard error

Table 3: Mean values of dermatoglyphic patterns of various groups

\begin{tabular}{|c|c|c|c|c|c|c|c|c|c|c|}
\hline \multirow[b]{2}{*}{ Various groups } & \multirow[b]{2}{*}{$N$} & \multicolumn{3}{|l|}{ Mean } & \multicolumn{3}{|l|}{$\underline{S D}$} & \multicolumn{3}{|l|}{$\underline{S E}$} \\
\hline & & Arches & Whorls & Loops & Arches & Whorls & Loops & Arches & Whorls & Loops \\
\hline Group I & 50 & 3.180 & 4.740 & 2.140 & 2.228 & 2.663 & 1.948 & 0.315 & 0.376 & 0.275 \\
\hline Group II & 50 & 2.720 & 4.420 & 2.860 & 1.852 & 2.634 & 2.213 & 0.261 & 0.372 & 0.313 \\
\hline Group III & 50 & 4.152 & 3.200 & 3.002 & 2.428 & 1.993 & 2.002 & 0.343 & 0.182 & 0.325 \\
\hline
\end{tabular}

Group I: CP caries-active children; group II: healthy caries-active children; group III: healthy caries-free children; SD: standard deviation; SE: standard error

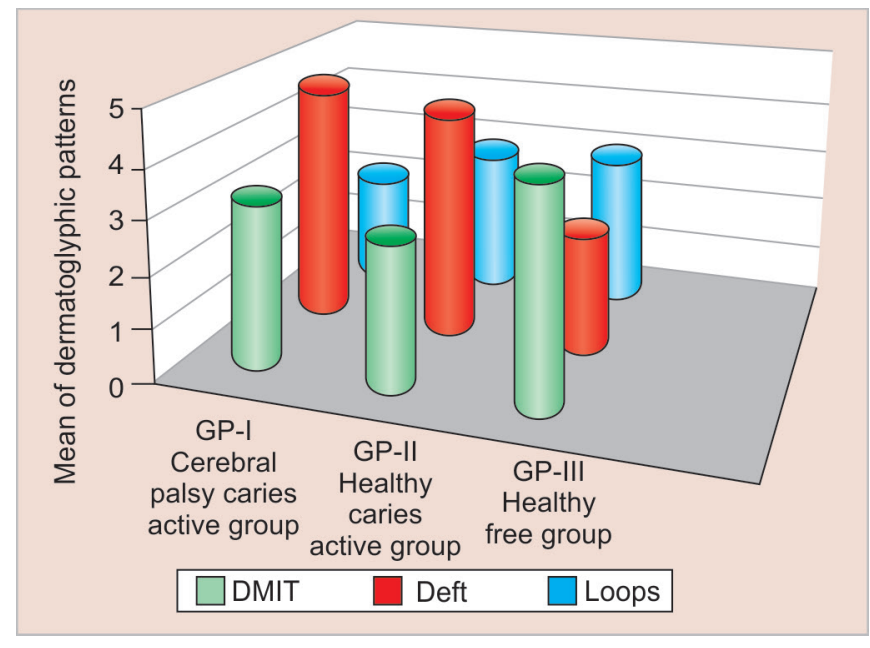

Fig. 6: Mean values of dermatoglyphic patterns

\section{Discussion}

$\mathrm{CP}$ is a common pediatric disorder that begins in childhood. It was first described in 1861 by the English orthopedist Dr William John Little. ${ }^{8}$ He coined the term CP in $1889^{9}$ where cerebral refers to the brain and palsy refers to the disorder of movement or posture. Inadequate functioning of the masticatory system in these children results in problems with mastication which requires constant consumption of mushy food added with decreased self-cleansing ability, leading to poor oral hygiene which in turn leads to increased susceptibility of dental caries in them. Moreover, these carious lesions keep on progressing as providing treatment is all the more difficult in these children.

In the present study, upon evaluation of dental caries status, it was found that the caries experience of CP children was higher than that of normal caries-active children and caries-free children. This is in accordance with the results of previous studies. A study done by Bhavsar et al. in Mumbai showed the prevalence and severity of dental caries to be the highest in the CP group. ${ }^{10}$ The dental status of CP children was investigated in the UK by Swallow in 1968, ${ }^{11}$ and it was found that these children had more number of unrestored teeth or extracted teeth than their healthy counterparts, which was
Table 4: Post-Tukey's analysis of intergroup comparison of various dermatoglyphic patterns of various groups

\begin{tabular}{llcll}
\hline $\begin{array}{l}\text { Dependent } \\
\text { variable }\end{array}$ & $\begin{array}{l}\text { Intergroup } \\
\text { comparison }\end{array}$ & Mean difference & SE & $p$-value \\
\hline ARCHES & Group I vs group II & 0.46000 & 0.436 & 0.294 \\
& Group I vs group III & -0.97200 & 0.436 & $0.000^{\mathrm{a}}$ \\
& Group II vs group III & -1.43200 & 0.436 & $0.000^{\mathrm{a}}$ \\
WHORLS & Group I vs group II & 0.32000 & 0.457 & 0.486 \\
& Group I vs group III & 1.27200 & 0.457 & $0.000^{\mathrm{a}}$ \\
& Group II vs Group III & 1.22000 & 0.457 & $0.000^{\mathrm{a}}$ \\
LOOPS & Group I vs group II & -0.72000 & 0.442 & 0.180 \\
& Group I vs group III & -0.86200 & 0.442 & 0.174 \\
& Group II vs group III & -0.14200 & 0.442 & 0.192 \\
\hline
\end{tabular}

${ }^{a}$ Statistically significant with $p$ value $\leq 0.05$; group I CP caries-active children; group II: healthy caries-active children; group III: healthy caries-free children; SE: standard error.

indicative of the difficulties that these children have in assessing dental care. Abanto et al., ${ }^{12}$ Ferraz et al., ${ }^{13}$ and Babu et al. ${ }^{14}$ have all reported higher caries experience in $\mathrm{CP}$ children.

Intergroup group comparison between the CP caries-active group and healthy caries-active group was found to be insignificant. The reason might be that the special children taken in group I (caries-active CP children) were institutionalized and each one of them had a personnel caretaker who monitored their diet and maintained their oral hygiene. So, in spite of them having poor neuromuscular incoordination, they had caries experience comparable to that of children in group II (healthy caries-active children). The results reported by Rao et al., ${ }^{15}$ both referring to mixed and permanent dentition, were comparable with the results obtained in this study. Grizic et al. ${ }^{16}$ also concluded that no significant difference between the CP children and control groups regarding caries experience was seen.

When intergroup comparison of group III (healthy cariesfree children) was done with group I (caries-active CP children) and group II (healthy caries-active children), it was found to be statistically significant (Table 2). This might be because in group III (healthy caries-free children), only those children were taken whose DMFT/deft was zero. 
Dermatoglyphics is the study of fingerprint patterns which helps in determining the susceptibility of a person to a genetic disease. Morphogenesis of dermatoglyphic structures like epidermal ridges occurs at the same time with the organogenesis of the fetal brain and tooth bud. Thus, the genetic message in the genome irrespective of it being normal or abnormal is deciphered during the same developmental period and is reflected by dermatoglyphics. Three types of epidermal ridge patterns were observed namely arches, whorls, and loops upon evaluation of dermatoglyphic patterns.

Intergroup comparison between all the three groups in terms of loops was found to be insignificant. So, to study dermatoglyphic patterns, in the present study, arches and whorls were taken into consideration.

Our results showed that with an increase in the arch pattern, the children had a decreased susceptibility to dental caries. Group III (healthy caries-free children) showed the maximum frequency of arches than group I (CP caries-active children) and group II (healthy caries-active children). Group III (healthy caries-free children) was the group comprising of caries-free children, and it has been proven in various studies that an increase in the number of arches indicates a decrease in susceptibility to caries. Upadhyaya et al. ${ }^{17}$ analyzed dermatoglyphic patterns in 300 children of the age group 5-12 years and had found an increased number of arches in the caries-free group. Previously, also similar results were reported by Madan et al., ${ }^{18}$ Singh et al., ${ }^{17}$ and Shetty et al. 2018, ${ }^{20}$ where individuals with increased arch patterns were less susceptible to caries.

In group I (CP caries-active children), the presence of arches was found to be more than in group II (healthy caries-active children), but less than in group III (healthy caries-free children). Studies have shown that the presence of $\mathrm{CP}$ is also associated with an increase in arches. But, in the present study, group I (CP caries-active group) is comprised of two genetic factors, namely $C P$ and susceptibility to caries. In CP, an increase in arches has been reported by Simsek et al. ${ }^{21}$ and Bhat et al. ${ }^{22}$ The second genetic factor which is susceptibility to caries has also been reported to be associated with a decrease in frequency of arches by Singh et al. ${ }^{19}$ and Chinmaya et al. ${ }^{4}$ They have observed a negative correlation of arches with dental caries. This cumulative effect might be the reason for the presence of more number of arches in group I (CP caries-active group) than in group II (healthy caries-active children).

The whorl pattern in the present study showed a steady increase in number with an increase in DMFT/deft scores, which was found to be maximum in CP children followed by healthy cariesactive children. It has been proven in studies done by Simsek et al. ${ }^{21}$ and Bhat et al. ${ }^{22}$ that the presence of CP is depicted by an increase in whorl patterns. Also, an association of an increase in whorl patterns with an increase in susceptibility to caries is established by various previous studies. Abhilash et al., ${ }^{23}$ Madan et al., ${ }^{18}$ Das et al., ${ }^{24}$ Gupta et al., ${ }^{17}$ and Yamuna Devi et al. ${ }^{25}$ found more whorl patterns in individuals with increased caries susceptibility.

In group II (healthy caries-active children), the mean value of whorls was found to be comparable with that in group I (CP cariesactive group). This can be attributed to the presence of a common genetic factor that is the presence of caries.

Group III (healthy caries-free group) showed the least number of whorls, and statistically significant results were obtained in the intergroup comparisons of group III (healthy caries-free group) with group I (CP caries-active group) and group II (healthy caries-active group). This might be because the children of group III (healthy caries-free children) were taken to be caries-free. Studies done by Anitha et al., ${ }^{26}$ Abhilash et al. ${ }^{23}$, Sengupta et al., ${ }^{27}$ and Maroli et al. ${ }^{28}$ have shown that an increase in the number of whorl patterns is associated with an increase in caries susceptibility.

Thus, dermatoglyphics may have a role in future in helping in the identification of CP children with or those at increased risk of caries, so that risk reduction measures are taken at an early stage.

\section{Limitations of the Study}

The study participants were all institutionalized, so the result of this in vivo study may not be the representative of the general CP children. Moreover, the study did not take into consideration the variations of the patterns with the severity of $C P$.

\section{Conclusion}

Within the limitations of this in vivo study, an association of dermatoglyphics and dental caries was observed in normal and CP children and the following conclusions were drawn.

- The whorls were found to be the highest for CP caries-active children and arches were found to be the highest for healthy caries-free children.

- When the intergroup comparison for the whorls and arches was done, it was found to be statistically insignificant between CP caries-active children and healthy caries-active children.

- DMFT/deft was found to be the highest for the CP caries-active children followed by the healthy caries-active group and was the least for the healthy caries-free group.

- When the intergroup comparison for DMFT/deft was done, it was found to be statistically significant among all the groups except when CP caries-active children and healthy caries-active children were compared.

\section{Clinical Significance}

The results of the present study raise awareness about the oral hygiene of the special children, especially CP and difficulty faced by the dentists in providing oral care to them. Dermatoglyphics, if used in such situations, would provide a vital component in the search for an acceptable, accurate, and cost-effective tool for the preliminary diagnosis, especially in diseases of suspected genetic origin-like dental caries and CP.

\section{Why this Article is Important to Pediatric Dentists}

Achievement and maintaining optimum oral health is the main obstacle in children with CP. This article highlights dermatoglyphics as a hope in the prediction of dental caries before its initiation, giving time to pediatric dentists to implement preventive measures before the caries sets in.

\section{What this Article Adds}

Considering the importance of dermatoglyphics and its correlation with dental caries in diseases with suspected genetic basis, it is important to spread awareness among dentists regarding the knowledge of dermatoglyphics. The results described in this article can help dentists to make use of dermatoglyphics as a noninvasive, inexpensive, and effective indicator for dental caries, especially in developing countries like India.

\section{References}

1. Sinha N, Singh, B, et al. Comparison of oral health status between children with cerebral palsy and normal children in India: a Case control study. J Indian Soc Perodontol 2015;10((1)):78-82. 
2. Kliegman, Behrman, et al. Nelson textbook of Pediatrics. Saunders Elseiver, 18th ed., 2008; 2494-2496.

3. Bretz W, Corby $P$, et al. Evidence of a contribution of genetic factors to dental caries risk. J Evid Based Dent Pract 2003 December;3((4)):185-189. DOI: 10.1016/j.jebdp.2003.11.002.

4. Chinmmaya B, Smitha S, et al. Dermatoglyphics: an indicator of dental caries in Humans. J Indian Assoc Public Health Dent 2016;14:272-275. DOI: 10.4103/2319-5932.187175.

5. Khokhar V, Gharvi T, et al. Dermatoglyphic interpretation of dental caries: An in vivo study. Int J Dent Med Res 2015 Mar-Apr 2015;1((16)):54-56.

6. Singh E, Saha $S$, et al. Association of Dermatoglyphic Peculiarities with dental Caries in Preschool Children of Lucknow, India. Int J Clin Pediatr Dent Jan-March 2016;9(1):39-44. DOI: 10.5005/jp-journals-10005-1331.

7. Prabhu N, Issrani R, et al. Dermatoglyphics in health and oral diseases. JSM Dent 2014;2(4):1044-1048.

8. Fernandes S, Marinho C, et al. Oral cavity Alterations Diagnosis in cerebral palsy subjects. JSM Health Education and primary Health Care 2017;2(2):1029-1032.

9. Sehrawat N, Marwaha K, et al. Cerebral palsy: a dental update. Int J Clin Pediatr Dent 2014;7(2):109-118. DOI: 10.5005/jp-journals-10005-1247.

10. Bhavsar JP, Damle SG., et al. Dental caries and oral hygiene amongst 12-14 years old handicapped children of Mumbai, India. J Indian Soc Pedod Prev Dent 1995;13(1):3.

11. Pope J, Curzon M, et al. The dental status of cerebral palsied children. Pediatr Dent May/June 1991;13:156-162.

12. Abanto J, Ortega AO, et al. Impact of oral diseases and disorders on oral health related quality of life of children with cerebral palsy. Spec Care Dentist 2014;34(2):56-63. DOI: 10.1111/scd.12028.

13. Ferraz NK, Tataoun off J, et al. Mechanical control of biofilm in children with cerebral palsy: a randomized control trial. Int J Pediatr Dent 2015;25:213-220. DOI: 10.1111/ipd.12132.

14. Subramanium $P$, Das $M$, et al. Assessment of Salivary Total Antioxidant Levels and oral health status in children with cerebral palsy. J Clin Pediatr Dent 2014;38:236-239. DOI: 10.17796/ jcpd.38.3.tv26g158q7343287.

15. Rao D, Hegde A, et al. Oral Hygiene of Disabled children and adolescents attending special schools of South Canara, India. Hong Kong Dent J 2005;2:107-113.
16. Grzic R, Bakarcić D, et al. Dental Health and Dental Care in Children with Cerebral Palsy. Coll. Antropol 2011;3:761-764.

17. Upadhyaya N, Gupta S, et al. Dermatoglyphics: a new diagnostic tool in dental caries prediction. EC Dent Sci 2017;14.4:174-180.

18. Madan N, Rathnam A, et al. Palmistry: a tool for dental caries prediction!. Indian J Dent Res 2011;22:213-218. DOI: 10.4103/09709290.84289.

19. Singh $E$, Saha $S$, et al. Association of Dermatoglyphic Peculiarities with dental Caries in Preschool Children of Lucknow, India. Int J Clin Paediatr Den Jan-March 2016;9(1):39-44. DOI: 10.5005/ jp-journals-10005-1331.

20. Shetty $C$, Hegde $M$, et al. Correlation between dental caries with salivary flow, $\mathrm{pH}$, and Buffering Capacity in Adult South Indian Population: An In vivo Study. Int J Res Ayurveda Pharm Mar-Apr 2013;4(2):219-223. DOI: 10.7897/2277-4343.04226.

21. Simsek S, Taskiran H, et al. Dermatoglyphic analyses in children with cerebral palsy. Indian J Forensic Med Toxicol 2012;6(2):24-28.

22. Bhat GH, Makhdoomi A, et al. Dermatoglyphics: in health and disease-a review. Int J Res Med Sci 2014;2(1):31-37. DOI: 10.5455/23206012.ijrms20140207.

23. Abhilash PR, Divyashree R, et al. Dermatoglyphics in Patients with dental caries: a study on 1250 individuals. J Contemp Dent Pract 2012;13(3):266-274. DOI: 10.5005/jp-journals-10024-1135.

24. Das N, Bezboruah G, et al. Study on the Clinical Profile of Patients with Cerebral Palsy. IOSR J Dent Med Sci July 2016;15(7):54-58. DOI: 10.9790/0853-150755458.

25. Yamuna D, Dineshshankar J, et al. Dermatoglyphic patterns and salivary $\mathrm{pH}$ in subjects with and without dental caries: a cross sectional study. J Nat Sci Biol Med July 2015;6:295-297. DOI: 10.4103/0976-9668.159979.

26. Anitha $C$, Konde S, et al. Dermatoglyphics: a genetic marker of early childhood caries. J Indian Soc Pedod Prev Dent Jul-Sep 2014;32(3):220-224.

27. Sengupta $A, B a z m i B$, et al. A cross sectional study of dermatoglyphics and dental caries in Bengalee children. J Indian Soc Pedod Prev Dent 2013;3:245-248. DOI: 10.4103/0970-4388.121823.

28. Maroli S, Korrai B, et al. An In vivo Investigation into an Inexpensive Diagnostic tool for predicting susceptibility to dental Caries. J Adv Oral Res Sep-Dec 2016;7(3):26-30. DOI: 10.1177/2229411220160305. 